\title{
Antiproliferation Effects of Nanophytosome-Loaded Phenolic Compounds From Fruit of Juniperus Polycarpos Against Breast Cancer in Mice Model: Synthesis, Characterization and Therapeutic Effects
}

\section{Soheila Moeini}

Islamic Azad University Mashhad Branch

Ehsan Karimi ( $\nabla$ ehsankarimi@mshdiau.ac.ir)

Islamic Azad University Mashhad Branch https://orcid.org/0000-0002-5011-9611

Ehsan Oskoueian

Arka Biotechnology Corporation

Research

Keywords: Drug delivery, phytogenic, phytosome, phenolic compound

Posted Date: November 17th, 2021

DOI: https://doi.org/10.21203/rs.3.rs-1073994/v1

License: (c) (1) This work is licensed under a Creative Commons Attribution 4.0 International License.

Read Full License 


\section{Abstract}

Background: This research was performed to synthesize nanophytosomes-loaded high phenolic fraction (HPF) from Juniperus polycarpos fruit extract and investigate its antiproliferation effects against breast cancer in mice model.

Results: The nanophytosomes-loaded HPF from Juniperus polycarpos fruit extract was synthesized. The mice trial was conducted to determine the possible toxic effects of the synthesized nanophytosomes. The anticancer, pro-apoptotic, and antioxidative activities of the nanophytosomes were determined. The nanophytosomes-loaded HPF had a spherical structure with a size of $176 \mathrm{~nm}$ and a polydispersity index coefficient of 0.24 . The in-vivo study manifested that nanophytosomes-loaded HPF significantly improved weight gain and food intake compared to the negative control group $(p<0.05)$. The nanophytosomes-loaded HPF significantly enhanced the expression of bax (3.4-fold) and caspase-3 (2.7fold) genes but reduced bcl2 (3.6-fold) gene expression in tumor cells. The average tumor size was significantly decreased in mice treated with nanophytosomes-loaded HPF $(p<0.05)$. The expression of GPX (2.3-fold) and SOD (2.7-fold) antioxidants in the liver of mice supplemented with nanophytosomesloaded HPF was significantly developed compared to the negative control $(p<0.05)$. The nanophytosomes-loaded HPF did not show toxicity on normal cells.

Conclusion: Our results indicated that nanophytosomes-loaded HPF might be a potential anticancer agent for the breast cancer treatment.

\section{Background}

Breast cancer is the second most common cancer in the world and the most common cancer among women worldwide [1]. It is also the second most common cause of cancer death among women globally [2]. In 2012, 1.67 million new breast cancer cases were identified worldwide, accounting for $25 \%$ of all cancers [2]. In recent years, some limitations, such as the high cost and side effects caused by synthetic chemical anticancer drugs, have forced scientists to search for new anticancer substances [3].

Plant secondary metabolites are rich sources of bioactive constituents utilized in the pharmaceutical industry, meal additives, flavors, and other industrial materials. These substances are also known to play an important role in adapting plants to their environment [4]. Bioactive natural compounds are employed to develop cheaper, safer, and more effective anti-inflammatory and anticancer drugs [5]. Among such natural chemical compounds, essential oils and phenolic and flavonoid components are proven beneficial antioxidants, antitumors, and anticancer. These compounds comprise several pharmacological properties that could prevent the creation of ROS and DNA damage and induce apoptosis through the caspase, P53, and other involved genes [6]. Plant secondary metabolites are regarded as potential chemopreventive agents which block cancer recurrence and prevent the development of invasive cancer. For these reasons, the global demand for herbal medicines is considerably increased [7]. 
Various technologies are adopted to promote and extract bioactive molecules in medicinal plants. Plantderived bioactive compounds are used as medicines, herbal chemicals, flavors, fragrances, food additives, and pesticides [8]. However, soluble, limited availability and absorption capacity and toxicity damage are significant obstacles in applying herbal medicine [8]. Fortunately, recent advances in nanotechnology provide excellent conditions to minimize these barriers in herbal medicine. For example, nanotechnology provides powerful systems for effective drug delivery through nanoparticles and nanostructures, e.g., liposomes, phytosomes, lipid transporter nanostructures, and solid lipid nanoparticles that carry anticancer components such as rutin, anthocyanins, catechins, and silymarin[9, 10].

Nanophytosomes are now considered valuable carriers of drugs and plant nutrients, and plant extracts [11]. The nanophytosome formulation is an ideal carrier for drug delivery because its nuclei are composed of phospholipids and cholesterol, similar to biological membranes [12-14]. Nano-based drug delivery system has advantages over traditional drug delivery systems. The nano-based systems have more efficient drug distribution, better-controlled drug release, and directly target cancer tissues with more excellent permeability and long-lasting effect[15]. In addition, nanophytosomes have biologically neutral structures and produce less immunogenic reactions.

Juniperus is one of the chief genera of the Cupressaceae family. It is estimated that 70 species of Juniperus are dispersed all over the world [16]. Juniperus is indicated in Iran by five species. Juniperus excelsa is divided into two subspecies including J. excelsa M. B subsp. excelsa and J. excelsa M. B subsp. Polycarpos. (Juniperus polycarpos, generally known as Persian juniper or "Ors "and is a dioecious tree up to 6-7 $\mathrm{m}$ high or a low shrub with dense head [17], additionally broadly dispensed in different areas such as south-east Arabia, Iran, Caucasus, Baluchistan, Afghanistan, north-west Himalaya [18]. The J. excelsa subsp. polycarpos is a medicinal plant used traditionally to cure different types of illness in animals and humans like asthma and earache. It has been articulated that the extracted compounds of $J$. excelsa subsp. polycarpos possess antimicrobial, antifungal, and antioxidant activities[19-21]. This study was performed to synthesize the nanophytosome-loaded phenolic compounds from the Juniperus polycarpos tree's fruit and evaluate its anticancer potential against breast cancer in Balb/c mice.

\section{Results}

\section{Fractionation and total phenolic content}

The different polarity fractions from Juniperus polycarpos fruit in different quantities were obtained. The highest total phenolic compounds (TPC) was detected in ethyl acetate fraction $298.4 \pm 2.16$ followed by $\mathrm{n}$ butanol $(127.3 \pm 5.76)>$ water $(63.4 \pm 8.59)>$ chloroform $(14.6 \pm 8.38)>$ hexane $(11.6 \pm 5.96) \mathrm{mg} \mathrm{GAE} / \mathrm{g} \mathrm{DW}$ of extract, respectively. The ethyl acetate fraction possessed the highest concentration of phenolic compounds hence named a high phenolic-rich fraction (HPF) and was used for further experiments. 


\section{Characterization of phytosomes}

The fractionation results indicated the ethyl acetate fraction as the highest concentration of phenolic compounds; hence the synthesis of phytosomes was performed using this fraction. Figure 1 demonstrates physical characteristics of nanophytosomes, including Z-average particle size (A), zeta potential (B), and FESEM image (C). The Zeta potential and particle size of nano phytosome-loaded by HPF were $-53.8 \mathrm{mV}$ and $176.34 \mathrm{~nm}$, respectively (Table 1). The polydispersity index, which is the particle size distribution index for the nanophytosome of HPF, was found to be 0.24 , which is in the range of the most suitable size for medical and pharmaceutical applications. The FESEM analysis confirmed that nanosize of phytosomes-loaded HPF, which were morphologically spherical and exhibited almost the same size, confirming the particle size results.

\section{Table 1}

Physical characteristics of nanophytosome-loaded high phenolic-rich fraction from Juniperus polycarpos fruit

Particle size (nm)

176.34
Polydispersity index (PDI)

0.24
Zeta potential (mV)

$-53.8$

\section{HPLC analysis}

The phenolic compounds profiling of nanophytosome-loaded HPF indicated different types of bioactive compounds (Table 2). The HPLC analysis revealed the presence of ellagic acid and ferulic acid as the major phenolic compounds with respective values of 923 and $713.5 \mu / \mathrm{g}$.

\section{Table 2}

Phenolic compounds present in the nanophytosome-loaded high phenolic-rich fraction from Juniperus polycarpos fruit

\section{Phenolic compounds $(\mu \mathrm{g} / \mathrm{g})$}

\section{Syringic acid}

$171.8 \pm 2.4$

Ellagic acid

$923 \pm 5.3$
Naringin

$509.5 \pm 4.5$

Cinnamic acid

$87.2 \pm 2.1$
Ferulic acid

$713.5 \pm 3.8$

Salicylic acid

$622.5 \pm 2.5$

\section{Toxicity assay}


The averages daily weight gain and daily food intake in each treatment are shown in Table 3 . The average daily weight gain and daily food intake showed significant $(p<0.05)$ differences between groups. The increase in the HPF concentration up to $50 \mathrm{mg} / \mathrm{kg} \mathrm{BW}$ significantly $(p<0.05)$ improved the averages daily weight gain and food intake as compared to the control. However, the application of HPF above 50 $\mathrm{mg} / \mathrm{kg}$ BW showed significant $(\mathrm{p}<0.05)$ determinantal effects on weight gain and food intake.

\section{Table 3}

The averages of mice body weight changes and food intake during experiment receiving different concentrations of high phenolic-rich fraction from Juniperus polycarpos fruit

\begin{tabular}{llllll} 
Average & M1 & M2 & M3 & M4 & SEM \\
\hline Average daily weight gain $(\mathrm{mg})$ & $22.3^{\mathrm{d}}$ & $37.5^{\mathrm{c}}$ & $67.3^{\mathrm{a}}$ & $60.2^{\mathrm{b}}$ & 4.59 \\
\hline Average daily food intake $(\mathrm{g})$ & $2.1^{\mathrm{c}}$ & $2.6^{\mathrm{b}}$ & $3.2^{\mathrm{a}}$ & $2.9^{\mathrm{a}}$ & 0.17
\end{tabular}

M1 (Control), M2 mice receiving HPF (25 mg TPC/ Kg/BW); M3 mice receiving HPF (50 mg $\mathrm{TPC} / \mathrm{Kg} / \mathrm{BW})$, and M4 mice receiving HPF (100 mg TPC/Kg/BW); Different letters in the same raw indicated significant difference $(p<0.05)$; the analysis was performed in triplicates

The liver enzymes (ALP, ALT, and AST) and MDA as lipid peroxidation values are considered biomarkers of hepatic damage and hepatotoxicity. The increase in HPF concentration up to $50 \mathrm{mg} \mathrm{TPC} / \mathrm{Kg} / \mathrm{BW}$ did not alter these parameters significantly ( $p>0.05)$ (Table 4). While the increase in the concentration of HPF above $50 \mathrm{mg} \mathrm{TPC} / \mathrm{Kg} / \mathrm{BW}$ significantly $(\mathrm{p}<0.05)$ impaired the liver enzymes and lipid peroxidation in the liver, which confirms the hepatic damage.

\section{Table 4}

The results of liver enzymes analysis and lipid peroxidation in the liver tissue of mice receiving different concentrations of high phenolic-rich fraction from Juniperus polycarpos fruit

\begin{tabular}{|llllll|}
\hline Parameters & M1 & M2 & M3 & M4 & SEM \\
\hline ALT (IU/L) & $154^{\mathrm{b}}$ & $153^{\mathrm{b}}$ & $165^{\mathrm{b}}$ & $188^{\mathrm{a}}$ & 7.63 \\
\hline AST (IU/L) & $62^{\mathrm{b}}$ & $64^{\mathrm{b}}$ & $68^{\mathrm{b}}$ & $71^{\mathrm{a}}$ & 4.9 \\
\hline ALP (IU/L) & $561^{\mathrm{b}}$ & $559^{\mathrm{b}}$ & $569^{\mathrm{b}}$ & $602^{\mathrm{a}}$ & 11.6 \\
MDA $^{*}(\%)$ & $100.0^{\mathrm{a}}$ & $91.4^{\mathrm{b}}$ & $79.6^{\mathrm{c}}$ & $96.8^{\mathrm{b}}$ & 7.68 \\
$\begin{array}{l}\text { M1 (Control), M2 mice receiving HPF (25 mg TPC/Kg/BW); M3 mice receiving HPF (50 mg } \\
\begin{array}{l}\text { TPC/Kg/BW), and M4 mice receiving HPF (100 mg TPC/Kg/BW); Different letters in the same raw } \\
\text { indicated significant difference (p<0.05); the analysis was performed in triplicates }\end{array}\end{array}$ \\
\hline
\end{tabular}

\section{Antiproliferative activity}


In the toxicity assay, we found that the concentration of $50 \mathrm{mg} \mathrm{TPC} / \mathrm{Kg} / \mathrm{BW}$ of high phenolic-rich fraction from Juniperus polycarpos fruit is not determinantal and toxic for the mice. Hence the antiproliferative activity of the HPF was performed using $50 \mathrm{mg} \mathrm{HPF} / \mathrm{Kg} / \mathrm{BW}$. The results of antiproliferative activities are presented in Table 5. The results indicated that nanophytosome-loaded HPF at $50 \mathrm{mg} \mathrm{TPC} / \mathrm{Kg} / \mathrm{BW}$ improved the average daily weight gain and food intake significantly $(p<0.05)$ compared to the control group. In addition, the nanophytosome-loaded HPF appeared to be more potent $(p<0.05)$ in improving the averages daily weight gain and food intake in the mice compared to the mice receiving un-capsulated HPF at the similar dose. The tamoxifen as an antiproliferative drug at the concentration of $0.4 \mathrm{mg} / \mathrm{kg} / \mathrm{BW}$ similar dose to the clinical dose in humans impaired $(p<0.05)$ the values for the average daily weight gain and food intake compared to the control group.

\section{Table 5}

The averages of body weight changes and food intake in the TUBO tumor-bearing mice during experiment receiving different treatments

\begin{tabular}{|c|c|c|c|c|c|}
\hline Average & $\mathrm{T} 1$ & $\mathrm{~T} 2$ & T3 & $\mathrm{T} 4$ & SEM \\
\hline Average daily weight gain (mg) & $63.4^{\mathrm{C}}$ & $78.9^{\mathrm{b}}$ & $94.2^{\mathrm{a}}$ & $42.6^{d}$ & 5.43 \\
\hline Average daily food intake (g) & $2.85^{\mathrm{c}}$ & $3.01^{\mathrm{b}}$ & $3.16^{\mathrm{a}}$ & $2.69^{d}$ & 0.06 \\
\hline \multicolumn{6}{|c|}{$\begin{array}{l}\text { Control (T1); mice receiving HPF ( } 50 \mathrm{mg} \text { TPC/Kg/BW) (T2); mice were receiving nanophytosome- } \\
\text { loaded HPF ( } 50 \mathrm{mg} \text { TPC/Kg/BW) (T3); and mice receiving tamoxifen }(0.4 \mathrm{mg} / \mathrm{kg} / \mathrm{BW} \text { similar dose to } \\
\text { the clinical dose in humans) as an antiproliferative drug (T4). Different letters in the same raw } \\
\text { indicated significant difference }(\mathrm{p}<0.05) \text {; The analysis was performed in triplicates }\end{array}$} \\
\hline
\end{tabular}

The results of liver enzymes (ALP, ALT, and AST) and MDA as lipid peroxidation value are considered as biomarkers of hepatocyte damage, and hepatotoxicity is shown in Table 6. These results showed that liver enzymes (ALP, ALT, and AST) and MDA were improved upon treatment of mice with HPF and nanophytosome-loaded HPF. However, the effectiveness of nanophytosome-loaded HPF was more prominent $(p<0.05)$ in alleviating these parameters compared to the HPF in the treated mice. However, the tamoxifen could suppress $(p<0.05)$ the liver enzymes and lipid peroxidation, the improvement was not comparable to that of unencapsulated and nanophytosome encapsulated HPF. 


\section{Table 6}

The results of liver enzymes analysis and lipid peroxidation in the liver tissue of TUBO tumor-bearing mice during experiment receiving different treatments

\begin{tabular}{|c|c|c|c|c|c|}
\hline Parameters & T1 & $\mathrm{T} 2$ & T3 & $\mathrm{T} 4$ & SEM \\
\hline ALT (IU/L) & $177^{a}$ & $145^{\mathrm{b}}$ & $123^{c}$ & $125^{c}$ & 8.72 \\
\hline AST (IU/L) & $63^{a}$ & $50^{\mathrm{b}}$ & $46^{\mathrm{b}}$ & $52^{b}$ & 4.18 \\
\hline ALP (IU/L) & $789^{a}$ & $466^{b}$ & $312^{c}$ & $455^{b}$ & 51.73 \\
\hline $\operatorname{MDA}^{*}(\%)$ & $100.0^{a}$ & $92.4^{\mathrm{b}}$ & $84.7^{c}$ & $94.6^{b}$ & 2.47 \\
\hline
\end{tabular}

\section{Tumors characteristics}

The histopathological changes of tumors in each group are depicted in Figure 2. In the T1 group, tumor areas were solid, with high cell density, without glandular structure. In the T2 group, cell density decreased, but differentiation did not change significantly. However, necrosis was more widespread than in the negative control, indicating the lethal effect of the HPF on cancer cells. Similarly, in the T3 group, cell density decreased, and differentiation did not show a significant change. However, necrosis has become more widespread than in the negative control and T2 groups, indicating that the nanophytosomeloaded HPF has a more lethal effect on necrotic cancer cells than the un-encapsulated HPF. In the T4 group, cell density decreased compared to the negative control, but cell differentiation increased, which seems to be due to cell apoptosis caused by the effect of tamoxifen. Glandular structures were formed, and the tumor was changed from the solid form in different areas, directly related to tamoxifen's antiproliferative effects.

A significant difference was observed in the mean of tumor weight and size between groups $(p<0.05)$. The control group collectively showed significantly higher tumor weight and larger size than other groups $(p<0.05 ;$ Table 7), revealing the antiproliferative effects of HPF and nanophytosome-loaded HPF. The weight and size of the tumor revealed that the nanophytosome-loaded HPF possessed more antiproliferative effects $(\mathrm{p}<0.05)$ than the un-encapsulated HPF. The T4 group exhibited the lowest mean tumor weight and size, followed by T3 and T2 groups (Table 7 \& Figure 3 ). 


\section{Table 7}

The size of tumor upon 28 days in TUBO tumor-bearing mice during experiment receiving different treatments

\begin{tabular}{llllll|} 
Tumor & T1 & T2 & T3 & T4 & SEM \\
\hline Weight $(\mathrm{g})$ & $3.4^{\mathrm{a}}$ & $2.94^{\mathrm{b}}$ & $2.63^{\mathrm{c}}$ & $1.59^{\mathrm{d}}$ & 0.16 \\
\hline Size $(\mathrm{mm})$ & $26.5^{\mathrm{a}}$ & $25.2^{\mathrm{b}}$ & $22.5^{\mathrm{c}}$ & $19.6^{\mathrm{d}}$ & 0.38
\end{tabular}

Control (T1); mice receiving HPF (50 mg TPC/Kg/BW) (T2); mice were receiving nanophytosomeloaded HPF (50 mg TPC/Kg/BW) (T3); and mice receiving tamoxifen ( $0.4 \mathrm{mg} / \mathrm{kg} / \mathrm{BW}$ similar dose to the clinical dose in humans) as an antiproliferative drug (T4).; Different letters in the same raw indicated significant difference $(p<0.05)$; The analyses were performed in triplicates

\section{Morphometric analysis of jejunum}

Morphometric analysis of jejunum in different groups is shown in Table 8. There was a significant difference in the mean size of villus height and width and crypt depth and goblet cells between groups $(p<0.05)$. These findings showed that the oral administration of HPF and nanophytosomes-loaded HPF notably $(p<0.05)$ improved the villus height, villus width, number of goblet cells, and decreased the crypt depth. These outcomes followed an earlier study [21] that informed that adding phenolic compounds in the animal diet improved the small intestine's morphometric parameters. Afterward, the intestinal absorption of nutrients is increased. Hence, the significant increase in the food intake and average daily weight gain of mice upon oral administration of fruit extract should enhance the morphology of the jejunum and enlargement the absorption of nutrients.

\section{Table 8}

Morphometric analysis of jejunum in TUBO tumor-bearing mice during experiments receiving different treatments.

\begin{tabular}{llllll} 
Treatment & T1 & T2 & T3 & T4 & SEM \\
\hline Villus Height $(\mu \mathrm{m})$ & $271.2^{\mathrm{c}}$ & $325.3^{\mathrm{b}}$ & $376.6^{\mathrm{a}}$ & $251.7^{\mathrm{c}}$ & 12.65 \\
\hline Villus Width $(\mu \mathrm{m})$ & $81.1^{\mathrm{c}}$ & $86.4^{\mathrm{b}}$ & $94.6^{\mathrm{a}}$ & $77.7^{\mathrm{c}}$ & 9.17 \\
\hline Crypt Depth $(\mu \mathrm{m})$ & $138.6^{\mathrm{a}}$ & $115.7^{\mathrm{b}}$ & $105.6^{\mathrm{c}}$ & $134.5^{\mathrm{a}}$ & 7.89 \\
\hline Goblet Cells $(\mu \mathrm{m})$ & $3.5^{\mathrm{b}}$ & $3.8^{\mathrm{a}}$ & $4.1^{\mathrm{a}}$ & $4.9^{\mathrm{a}}$ & 0.71 \\
\hline
\end{tabular}

Control (T1); mice receiving HPF (50 mg TPC/Kg/BW) (T2); mice were receiving nanophytosomeloaded HPF (50 mg TPC/Kg/BW) (T3); and mice receiving tamoxifen ( $0.4 \mathrm{mg} / \mathrm{kg} / \mathrm{BW}$ similar dose to the clinical dose in humans) as an antiproliferative drug (T4). 


\section{Gene expression analysis}

Gene expression analysis showed a significant difference in the expression pattern of bax, bcl2, and caspase-3 between groups ( $p<0.001$; Table 9 ). Mice treated with HPF, nanophytosomes-loaded HPF, and tamoxifen showed significant down-regulation of $b c l 2(p<0.001)$ and overexpression of bax and caspase3 genes as compared to the control group $(p<0.01)$. However, the highest increase in bax and caspase- 3 gene expression was found in the T4 group, followed by T3 and T2 groups. Compared to the control group, tamoxifen caused a significant increase in bax and caspase-3 expression by 4.8-fold and 3.9-fold, respectively $(p<0.001)$. In contrast, mice treated with tamoxifen showed a significant decrease in bcl2 expression by 5.2 -fold rather than animals in the control group $(p<0.001 ;$ Table 9$)$. Similar to tamoxifen, nano phytosome-loaded extract significantly enhanced bax (3.4-fold) and caspase-3 (2.7-fold) expression but decreased bcl2 expression by 3.6-fold $(p<0.05)$.

\section{Table 9}

The changes in the expression of apoptosis-related genes in the TUBO tumor in the mice receiving different treatments.

\section{Gene expression (Fold changes)}

Genes

Up-regulated genes

$\mathrm{T} 1$ $1.0^{\mathrm{d}}$

$1.0^{\mathrm{d}}$

$2.6^{\mathrm{c}}$

$3.4^{\mathrm{b}}$

$4.8^{\mathrm{a}}$

$3.9^{a}$

$2.7^{b}$

$1.9^{\mathrm{c}}$

$2.3^{c}$

$3.6^{\mathrm{b}}$

$5.2^{\mathrm{a}}$

008

Control (T1); mice receiving HPF (50 mg TPC/Kg/BW) (T2); mice were receiving nanophytosomeloaded HPF (50 mg TPC/Kg/BW) (T3); and mice receiving tamoxifen $(0.4 \mathrm{mg} / \mathrm{kg} / \mathrm{BW}$ similar dose to the clinical dose in humans) as an antiproliferative drug (T4).; Different letters in the same raw indicated significant difference $(\mathrm{p}<0.05)$; The analysis was performed in triplicates

A significant difference was seen in the expression pattern of SOD and GPX Genes between groups ( $p<0.001$; Table 10). Mice treated with HPF, nanophytosomes-loaded HPF, and tamoxifen showed significant overexpression of SOD and GPX compared to the control group $(p<0.05)$. The highest increase in SOD and GPX gene expression was found in the T3 group, followed by T4 and T2 groups. Compared to the control group, nanophytosomes-loaded HPF caused a significant increase in SOD and GPX expression by 2.7 -fold and 2.3-fold, respectively $(\mathrm{p}<0.001)$. 


\section{Table 10}

The changes in the expression of antioxidant-related genes in mice liver receiving different treatments

\section{Gene expression (Fold changes)}

$\begin{array}{llllll}\text { Genes } & \text { T1 } & \text { T2 } & \text { T3 } & \text { T4 } & \\ \text { SOD } & 1.0^{\mathrm{c}} & 1.9^{\mathrm{b}} & 2.7^{\mathrm{a}} & 2.1^{\mathrm{b}} & 0.11 \\ \text { GPX } & 1.0^{\mathrm{d}} & 1.4^{\mathrm{c}} & 2.3^{\mathrm{a}} & 1.8^{\mathrm{b}} & 0.09\end{array}$

Control (T1); mice receiving HPF (50 mg TPC/Kg/BW) (T2); mice were receiving nanophytosomeloaded HPF (50 mg TPC/Kg/BW) (T3); and mice receiving tamoxifen ( $0.4 \mathrm{mg} / \mathrm{kg} / \mathrm{BW}$ similar dose to the clinical dose in humans) as an antiproliferative drug (T4).; Different letters in the same raw indicated significant difference $(\mathrm{p}<0.05)$; The analysis was performed in triplicates

\section{Discussion}

This research considered the effect of HPF and nanophytosomes-loaded HPF obtained from $\mathrm{J}$. polycarpos fruit against breast cancer cells growth and apoptotic biomarkers. Our results showed that phenolic rich fraction from J. polycarpos fruit, especially at a concentration of $50 \mathrm{mg} \mathrm{TPC} / \mathrm{Kg} / \mathrm{BW}$, significantly mitigates lipid peroxidation status and level of liver enzymes. While untreated mice revealed higher liver enzymes and MDA contents in their blood, mice supplemented with HPF, and nanophytosomes-loaded HPF showed a significant decrease in the average of MDA and liver enzymes. Additionally, the expression of antioxidant enzymes, SOD and GPX, was significantly increased in the liver of mice after supplementation with nanophytosomes-loaded HPF. These findings indicate that nanophytosomes-loaded HPF has a protective effect on body organs by reducing oxidative damage and improving the antioxidant capacity. In a study, Mrid et al. [22] assessed the antioxidant properties of aqueous and methanol extracts of needles and berries of $J$. oxycedrus on breast cancer cell lines. They demonstrated that $J$. oxycedrus extract significantly improved the activity of SOD and GPX.

Moreover, the plant extract showed potent cytotoxic effects against breast cancer cell lines with no cytotoxicity towards normal cells. These results are closely consistent with the findings of our research. In our study, the extracts exhibited intense antioxidant activity.

Furthermore, nanophytosomes-loaded HPF exhibited a cytotoxicity effect on breast cancer cells with no toxic effects. In our study, mice receiving nanophytosomes-loaded HPF showed a higher average weight gain and food intake than the control group. These findings implicate the beneficial of nanophytosomesloaded HPF for the normal growth of body organs. To improve the antitumor activity of HPF, we loaded the HPF into a nanophytosome. Interestingly, our data revealed that nanophytosomes-loaded HPF has a significant effect in inducing apoptosis in the tumor tissue. We found that the nanophytosomes-loaded HPF not only decreased the expression of an anti-apoptotic biomarker bcl2, but also enhanced apoptotic biomarkers bax and caspase-3, in tumor tissue without any toxicity on normal cells. Besides, Thus, this finding emphasizes that nanophytosomes-loaded HPF can effectively target and inhibit tumor cells 
growth by inducing the apoptotic biomarkers. Some studies reported the antitumor effect of $J$. polycarpos fruit extracts on various cancer cell lines to support these findings. Benzina et al. [23] considered the apoptotic properties of the flavonoid deoxypodophyllotoxin purified from the J. communis extract on MB231 breast cancer cells. They found that the extract induces cancer cells apoptosis by inducing the caspase-3 pathway.

Similarly, we found that J. polycarpos HPF, especially nanophytosomes-loaded HPF, significantly promoted apoptosis via inducing the expression of the caspase-3 gene. More recently, Huang et al. [24] evaluated the antiproliferation and anti-metastasis efficacy of hinokiflavone compound extracted from J. phoenicea on human breast cancer cells. They reported that hinokiflavone significantly inhibited proliferation and induced apoptosis in breast cancer cells by modulating bax/bcl 2 ratio. In addition, hinokiflavone remarkably inhibited migration and invasion of breast cancer cells. In our study, nanophytosomes-loaded HPF significantly enhanced the expression of bax and reduced the bcl 2 gene in tumor cells. These effects were comparable with the standard chemical tamoxifen drug.

\section{Conclusion}

In conclusion, we found that the HPF is very rich in phenolic metabolites. Furthermore, these extracts exhibited strong antioxidant capacity. Interestingly, HPF decreased lipid peroxidation and exhibited a protective effect on liver tissue by reducing the levels of liver-specific enzymes in a dose-dependent manner. To understand and improve the characteristic of the cytotoxicity effect of the HPF on human breast cancer cell lines, we incorporated these extracts of nanophytosome. Analysis of cytotoxic activity revealed a potential cytotoxic effect of nanophytosomes-loaded HPF against breast tumor cells lines. However, the nanophytosomes-loaded HPF appears to be not cytotoxic towards normal cells. We also found that nanophytosomes-loaded HPF induced apoptosis of tumor cells through overexpression of bax and caspase-3 genes and down-regulation of bcl2. It appears that overproduction of reactive oxygen species, lipid peroxidation, and consequently induction of apoptosis pathways may be a potential action of nanophytosomes-loaded HPF to inhibit tumor cell growth and proliferation. According to all the above results, it can be concluded that nanophytosomes-loaded HPF could offer a beneficial and natural source of bioactive compounds that can be either used on the preventive side as used in the clinic without toxicity.

\section{Material And Methods}

\section{Plant material}

Juniperus polycarpos fruits were collected from Chah chaheh, Razavi Khorasan Province, Iran, with the GPS location of $36.58608660658901,60.37961020210671$ on July 2020. The fruits of Juniperus polycarpos were identified and confirmed by the laboratory of plant taxonomy staff at the herbarium of Khorasan Razavi Agricultural and Natural Resources Research and Education Center, AREEO, Mashhad, Iran. The fruits were then rinsed and air-dried in a shady place at $25^{\circ} \mathrm{C}$ for 10 days. Cholesterol, methanol, 
soybean phosphatidylcholine, and dichloromethane were bought from Merck Company (Darmstadt, Germany). All the other solvents and chemicals for this study were purchased from Sigma-Aldrich (Germany).

\section{Extraction}

Dried fruits were ground by a laboratory grinder to the fine powder and were extracted utilizing $80 \%$ methanol as solvent as described earlier by Crozier et al. [25]. Briefly, a dried sample of $0.5 \mathrm{~g}$ was weighed and placed into a $100 \mathrm{ml}$ conical flask. Forty $\mathrm{ml}$ of $80 \%(\mathrm{v} / \mathrm{v})$ methanol was added, followed by $10 \mathrm{ml}$ of 6 $\mathrm{M} \mathrm{HCl}$. The combination was stirred using a magnetic stirrer. The mixture was placed in a Round-bottom flask and attached to reflux and extracted for $2 \mathrm{~h}$ at $90^{\circ} \mathrm{C}$, after which the mixture was filtered utilizing Whatman No.1 filter paper (Whatman, England), and the filtrate was then taken to dryness with the aid of a vacuumed Rotary Evaporator (Buchi, Switzerland) at $60^{\circ} \mathrm{C}$.

\section{Extract fractionation}

The extract was fractioned using a separating funnel using hexane, chloroform, ethyl acetate, n-butanol, and water, as shown in Figure 4. Each extraction was performed with $200 \mathrm{ml}$ of fresh solvent, and the extraction for each solvent was carried out in triplicate. The obtained extract was filtered with Whatman No.1 filter paper and concentrated with the aid of a vacuum rotary evaporator (Buchi, Switzerland). The fractions were then dried in a freeze dryer and kept at $-20{ }^{\circ} \mathrm{C}$ for total phenolic analysis. Each fraction's total phenolic compounds (TPC) evaluation was carried out by adding $0.1 \mathrm{ml}$ of the extract, $2.5 \mathrm{ml}$ of Folin-Ciocalteu reagent $(1: 10 \mathrm{v} / \mathrm{v})$, and $2 \mathrm{ml}$ of $7.5 \%$ SODium carbonate into a test tube covered with aluminum foil. The test tubes were vortexed, and the absorbance was measured at $765 \mathrm{~nm}$ [26]. The results were expressed as milligrams of gallic acid equivalents (GAE) per gram dry weight of each fraction. The fraction containing the highest phenolic content is named a phenolic rich fraction (HPF). The test tubes were vortexed, and the absorbance was measured at $765 \mathrm{~nm}$. The results were expressed as milligrams of gallic acid equivalents (GAE) per gram dry weight of each fraction. The fraction containing the highest phenolic content is named a phenolic rich fraction (HPF).

\section{Nanophytosomes preparation}

Phytosomes can be produced by reacting phospholipids (1-3 mol) with an active substance $(1 \mathrm{~mol})$ in an aprotic solvent. In this study, nanophytosomes of HPF were produced in a ratio of 3:1 in ethyl acetate as an aprotic solvent. The complex was placed on a shaker overnight at a temperature of $55-60^{\circ} \mathrm{C}$ to dissolve completely. After removing the solvent using a freeze dryer, nanophytosomes were formed. The dynamic light scattering (DLS) technique was performed to ascertain particles' average size and stability (zeta potential). The measurements were examined three times by a Malvern Zetasizer Nano ZS (Malvern, 
UK). Furthermore, field emission scanning electron microscopy (FESEM) was applied to determine the size and shape of the nanophytosomes.

\section{Phenolic profiling of nanophytosome}

To determine the phenolic compounds present in the nanophytosome the analysis was performed by Reversed-Phase High-Performance Liquid Chromatography (RP-HPLC). The phenolic standards used in this study were gallic acid, syringic acid, vanillic acid, salicylic acid, caffeic acid, pyrogallol, catechin, cinnamic acid, ellagic acid, naringin, chrysin, and ferulic acid. The solvents consisted of deionized water (solvent A) and acetonitrile (solvent B). The column was eluted and equilibrated by $85 \%$ solvent $A$ and 15 $\%$ solvent $B$ for 20 min before injection. Then, the ratio of solvent $B$ was increased to $85 \%$ after 60 min. After $5 \mathrm{~min}$ (at the $65^{\text {th }}$ minute of running the experiment), the ratio of solvent $\mathrm{B}$ was reduced to $15 \%$. This ratio was maintained for $70 \mathrm{~min}$ for the following analysis with a $1 \mathrm{ml} / \mathrm{min}$ flow rate. An analytical column (Intersil ODS-3 5um 4.6×150 mm GI Science Inc. USA) was used to detect phenolic compounds at $280 \mathrm{~nm}$.

\section{Toxicity assay}

This assay was conducted to determine the toxicity of HPF using mice as an animal model. The 24 female Balb/c mice (at 4 weeks of age) were bought from the laboratory of the animal research center at Razi Vaccine and Serum Research Institute (Mashhad, Iran). Mice were adapted to the lab environment for one week and then randomly divided into 4 groups, including M1 (Control), M2 (25 mg/Kg/BW HPF); M3 (50 mg TPC/Kg/BW HPF), and M4 (100 mg/Kg/BW HPF). Mice were housed 3 per cage $(30 \times 15 \times 15$ $\mathrm{cm}$ ) in a standard climate room (temperature of $22 \pm 2^{\circ} \mathrm{C}$, humidity $50 \% \pm 5 \%$, and a $12: 12 \mathrm{light} / \mathrm{dark}$

cycle) and had free access to food and tap water. 48 hours after the final treatment (day 28), mice were anesthetized, and blood samples were directly collected from the abdominal aorta to measure blood tests analysis using a blood auto-analyzer (Hitachi 902, Japan). Liver, kidney, intestine, spleen tissues were isolated and fixed in 10\% formalin for at least 48 hours. Hematoxylin-eosin (H\&E) staining was applied for morphological and histological examination of all tissues. The toxicity survey test was carried out in compliance with the OECD guideline No. 407. The mice trial in this research was approved by the ethical committee of Azad university of Mashhad and the laws, norms, and regulations dealing with international animal ethics (IR.IAU.MSHD.REC.1400.087).

\section{Antiproliferative activity}

To study the antiproliferative activity of HPF and phytosomes-loaded HPF, thirty-two female BALB/c mice (with an average age of 28 days and an average body weight of $19 \mathrm{~g}$ ) were purchased from the laboratory animal research center at Razi Vaccine and Serum Research Institute (Mashhad, Iran). Upon one week of adaptation, the mice were randomly divided into four groups, animals in each group were 
housed 2 per cage $(30 \times 15 \times 15 \mathrm{~cm})$ in a standard climate room (temperature of $22 \pm 2^{\circ} \mathrm{C}$, humidity $50 \%$ $\pm 5 \%$, and a 12:12 light/dark cycle) and had free access to food and tap water. A cancerous cell line (TUBO breast cancer cell line) was obtained from Pasteur Institute (Tehran, Iran), and cultured in RPMI 1640 medium (Gibco, USA), supplemented with 10\% inactivated fetal bovine serum (FBS) (Gibco, USA), $10 \%$ penicillin/streptomycin (100000 U/L) (Gibco, USA). Cells were grown at $37^{\circ} \mathrm{C}$, under a $5 \% \mathrm{CO}_{2}$ atmosphere, and at $90 \%$ humidity for $24 \mathrm{~h}$ to reach $\sim 80 \%$ confluency. Neubauer hemocytometer method was used to count cells. A total number of $5 \times 10^{5}$ TUBO breast cancer cells (in a volume of $50 \mu \mathrm{l}$ PBS buffer) were injected subcutaneously to the right flank of all animals. When the tumor size reached about $3 \mathrm{~mm}$, the following treatments were applied for 28 days through daily gavage: control (T1); mice were receiving HPF (50 mg TPC/Kg/BW) (T2); mice were receiving nanophytosome-loaded HPF (50 mg $\mathrm{TPC} / \mathrm{Kg} / \mathrm{BW})(\mathrm{T} 3)$, and mice receiving tamoxifen $(0.4 \mathrm{mg} / \mathrm{kg} / \mathrm{BW}$ similar dose to the clinical dose in humans) as an antiproliferative drug (T4). The treatments were applied every day through oral gavage. All treatments received standard and balanced food pellets with free access to water. The corn oil was selected as a carrier of HPF and phytosomes. The control group has received corn oil devoid of HPF or phytosomes. Mice were monitored weekly by measuring tumor size using a digital caliper, and the tumor volume was also calculated by the following formula: [(length $\times$ width $\times$ height $) \times 0.52$ ]. The food intake and weight changes were determined weekly. According to the laws, norms, and regulations dealing with international animal ethics, all the procedures used in animal trials in this research were assessed and accepted by the ethical committee of the Islamic Azad University of Mashhad, Iran.

\section{Samples collection}

At the end of the experiment, mice were anesthetized, and blood samples were collected from the abdominal aorta to measure blood tests analysis. Liver, kidney, intestine, spleen, and tumor tissues were isolated for histological examinations and gene expression analysis. For histological examination, tissues were removed and fixed in 10\% formalin for at least 48 hours. Fragments were dehydrated in graded ethanol series, embedded in paraffin, and sectioned using an automatic microtome at 4-5 mm thickness. For histological processing, the sectioned tissues were stained with hematoxylin-eosin (H\&E) and examined for morphological and histological parameters by light microscopy. For gene expression analysis, a fragment of tissues $(50-100 \mathrm{mg}$ ) was isolated and immediately froze in the liquid nitrogen and kept at -80 for the gene expression analysis. The liver enzymes in the serum, such as alanine aminotransferase (ALT), alkaline phosphatase (ALP), and aspartate transaminase (AST), were determined using a blood auto-analyzer (Hitachi 902, Japan). The malondialdehyde (MDA) was determined as a marker of oxidative stress in the liver tissue [27]. In brief, the liver tissue was homogenized, and $200 \mu \mathrm{l}$ of lysate were mixed with $300 \mu \mathrm{l}$ of water, $35 \mu \mathrm{l}$ of BHT, $165 \mu \mathrm{l}$ of SODium dodecyl sulfate, and $2 \mathrm{ml}$ of thiobarbituric acid, respectively. Upon heating $\left(90^{\circ} \mathrm{C}\right.$ for $\left.60 \mathrm{~min}\right)$, the solution was mixed with $2 \mathrm{ml}$ of $\mathrm{n}$-butanol and centrifuged at $3000 \times \mathrm{g}$ for $5 \mathrm{~min}$. The absorbance of the $\mathrm{n}$-butanol part was determined at $523 \mathrm{~nm}$, and the results were expressed as percentage malondialdehyde (MDA) changes relative to the control. 


\section{Gene expression analysis}

The total RNA was extracted using AccuZol ${ }^{\mathrm{TM}}$ Total RNA Extraction Reagent kit (Bioneer Company, South Korea). The quantity and quality of extracted RNAs were evaluated using a Nanodrop spectrophotometer (Biotek Instruments). Electrophoresis, a fraction of each RNA sample on 1\% denaturing agarose gel stained with ethidium bromide, was used to analyze the quality of RNAs. The cDNA synthesis kit (Fermentas, USA) containing RevertAid RT Reverse Transcription and Oligo dT primer was used for cDNA synthesis from RNA $(5 \mu \mathrm{g})$ at $42^{\circ} \mathrm{C}$ for $1 \mathrm{~h}$. A Rotor-Gene 6000 (CFX 96 Real-Time System) thermocycler in 36 cycles was applied for amplification. Each reaction included $10 \mu \mathrm{L} 2 \mathrm{X}$ master mix, and $10 \mathrm{pmol}$ primers, $1 \mu \mathrm{l}$ template CDNA, and $8.2 \mu \mathrm{ddH}_{2} \mathrm{O}$ in a total volume of $20 \mu \mathrm{l}$. Primer sequences of studied genes are shown in Table 11. The mRNA expression levels of selected genes were normalized to the expression of either $\beta$-actin (for the mice genes) or GAPDH (for the human gene) as a house-keeping gene. The relative expression of studied genes was calculated using the $2^{-\Delta \mathrm{Ct}}$ method [28].

\section{Table 11}

Primers sequences used in this study

\begin{tabular}{llll}
\hline Genes & & Forward $\left(5^{\prime}\right.$ to $\left.3^{\prime}\right)$ & Reverse $\left(5^{\prime}\right.$ to $\left.3^{\prime}\right)$ \\
\hline Mice & SOD & gagacctgggcaatgtgact & gtttactgcgcaatcccaat \\
\cline { 2 - 4 } & GPX & gtccaccgtgtatgccttctcc & tctcctgatgtccgaactgattgc \\
\cline { 2 - 4 } & B-actin & ggtcggtgtgaacggatttgg & atgtaggccatgaggtccacc \\
\hline \multirow{2}{*}{ Human } & bax & tttgcttcagggtttcatcca & ctccatgttactgtccagttcgt \\
\cline { 2 - 4 } & bcl2 & catgtgtgtggagagcgtcaac & cagataggcacccagggtgat \\
\hline & caspase-3 & ctggactgtggcattgagac & acaaagcgactggatgaacc \\
\hline & GAPDH & ccggatcgaccactacctgggcaac & gttccccacgtactggcccaggacca
\end{tabular}

\section{Statistical Analysis}

All data were presented as means \pm SD. The One-Way ANOVA: Post Hoc-Tukey test was used to compare the mean of all data between groups. Data were analysed using SPSS software (version 19). A p $<0.05$ was considered significant.

\section{Declarations}

\section{Ethics approval and consent to participate}


This research does not contain any studies with human participants performed by any of the authors. All applicable international and national guidelines for the care and use of animals were followed. Research on experimental animals was carried out with the consent of the local ethics committee for animal experiments. All animal handling method was accomplished as per the regulations of the Islamic Azad University of Mashhad, IRAN. Consent to participate-NA/Not applicable

\section{Consent to Publication:}

Not applicable

\section{Availability of data and materials}

The datasets applied during the current study are available on reasonable request.

\section{Competing interests}

The authors declare that they have no competing interests.

\section{Funding}

There has been no financial support for this work.

\section{Authors' contributions}

SM: Study design, experimental work, formal analysis and writing original draft; EK and EO: analysis, methodology, project administration, supervision, review, and editing of the original draft; All authors read and approved the final manuscript. All authors contributed equally to this work

\section{Acknowledgements}

The authors are grateful to the Islamic Azad University of Mashhad for the laboratory facilities.

\section{References}

1. Dumitrescu R, Cotarla I: Understanding breast cancer risk-where do we stand in 2005 ? Journal of cellular and molecular medicine 2005, 9:208-221.

2. Momenimovahed $\mathrm{Z}$, Salehiniya $\mathrm{H}$ : Epidemiological characteristics of and risk factors for breast cancer in the world. Breast Cancer: Targets and Therapy 2019, 11:151. 
3. Enyew A, Asfaw Z, Kelbessa E, Nagappan R: Ethnobotanical study of traditional medicinal plants in and around Fiche District, Central Ethiopia. Current Research Journal of Biological Sciences 2014, 6:154-167.

4. Selvakumar P, Badgeley A, Murphy P, Anwar H, Sharma U, Lawrence K, Lakshmikuttyamma A: Flavonoids and other polyphenols act as epigenetic modifiers in breast cancer. Nutrients 2020, 12:761.

5. Wangchuk $P$ : Therapeutic applications of natural products in herbal medicines, biodiscovery programs, and biomedicine. Journal of Biologically Active Products from Nature 2018, 8:1-20.

6. Roleira FM, Tavares-da-Silva EJ, Varela CL, Costa SC, Silva T, Garrido J, Borges F: Plant derived and dietary phenolic antioxidants: Anticancer properties. Food Chemistry 2015, 183:235-258.

7. CB MN, Zingue S, Winter E, Creczynski-Pasa T, Michel T, Fernandez X, Njamen D, Clyne C: Flavonoids, Breast Cancer Chemopreventive and/or Chemotherapeutic Agents. Current Medicinal Chemistry 2015, 22:3434-3446.

8. Niazian M: Application of genetics and biotechnology for improving medicinal plants. Planta 2019, 249:953-973.

9. Babazadeh A, Ghanbarzadeh B, Hamishehkar H: Formulation of food grade nanostructured lipid carrier (NLC) for potential applications in medicinal-functional foods. Journal of Drug Delivery Science and Technology 2017, 39:50-58.

10. Babazadeh A, Ghanbarzadeh B, Hamishehkar H: Novel nanostructured lipid carriers as a promising food grade delivery system for rutin. Journal of Functional Foods 2016, 26:167-175.

11. Babazadeh A, Zeinali M, Hamishehkar H: Nano-phytosome: a developing platform for herbal anticancer agents in cancer therapy. Current drug targets 2018, 19:170-180.

12. Sindhumol $P$, Thomas $M$, Mohanachandran P: Phytosomes: a novel dosage form for enhancement of bioavailability of botanicals and neutraceuticals. International Journal of Pharmacy and Pharmaceutical Sciences 2010, 2:10-14.

13. Kulkarni GT: Herbal drug delivery systems: An emerging area in herbal drug research. Journal of Chronotherapy and Drug Delivery 2011, 2:113-119.

14. Ghanbarzadeh B, Babazadeh A, Hamishehkar H: Nano-phytosome as a potential food-grade delivery system. Food bioscience 2016, 15:126-135.

15. Weinberg OK, Marquez-Garban DC, Pietras RJ: New approaches to reverse resistance to hormonal therapy in human breast cancer. Drug resistance updates 2005, 8:219-233.

16. Topçu G, Erenler R, Çakmak O, Johansson CB, Çelik C, Chai H-B, Pezzuto JM: Diterpenes from the berries of Juniperus excelsa. Phytochemistry 1999, 50:1195-1199.

17. Emami SA, Abedindo BF, Hassanzadeh-Khayyat M: Antioxidant activity of the essential oils of different parts of Juniperus excelsa M. Bieb. subsp. excelsa and J. excelsa M. Bieb. subsp. polycarpos (K. Koch) Takhtajan (Cupressaceae). Iranian journal of pharmaceutical research: IJPR 2011, 10:799. 
18. Tutin T, Heywood V, Burges N, Moore D, Valentine D, Walters S, Webb D: 1980: Flora Europaea. Cambridge: Univ Press 1964, 1:428.

19. Moein M, Ghasemi Y, Moein S, Nejati M: Analysis of antimicrobial, antifungal and antioxidant activities of Juniperus excelsa M. B subsp. Polycarpos (K. Koch) Takhtajan essential oil. Pharmacognosy research 2010, 2:128.

20. Hosseinihashemi S, Dadpour A, Lashgari A: Antioxidant activity and chemical composition of Juniperus excelsa ssp. polycarpos wood extracts. Natural product research 2017, 31:681-685.

21. Mohiti-Asli M, Ghanaatparast-Rashti M: Comparing the effects of a combined phytogenic feed additive with an individual essential oil of oregano on intestinal morphology and microflora in broilers. Journal of Applied Animal Research 2018, 46:184-189.

22. Ben Mrid R, Bouchmaa N, Bouargalne Y, Ramdan B, Karrouchi K, Kabach I, El Karbane M, Idir A, Zyad A, Nhiri M: Phytochemical characterization, antioxidant and in vitro cytotoxic activity evaluation of Juniperus oxycedrus Subsp. oxycedrus needles and berries. Molecules 2019, 24:502.

23. Benzina S, Harquail J, Jean S, Beauregard A-P, D Colquhoun C, Carroll M, Bos A, A Gray C, A Robichaud G: Deoxypodophyllotoxin isolated from Juniperus communis induces apoptosis in breast cancer cells. Anti-Cancer Agents in Medicinal Chemistry (Formerly Current Medicinal Chemistry-AntiCancer Agents) 2015, 15:79-88.

24. Huang W, Liu C, Liu F, Liu Z, Lai G, Yi J: Hinokiflavone induces apoptosis and inhibits migration of breast cancer cells via EMT signalling pathway. Cell biochemistry and function 2020, 38:249-256.

25. Crozier A, Lean ME, McDonald MS, Black C: Quantitative analysis of the flavonoid content of commercial tomatoes, onions, lettuce, and celery. Journal of agricultural and food chemistry 1997, 45:590-595.

26. Oskoueian E, Karimi E, Noura R, Ebrahimi M, Shafaei N, Karimi E: Nanoliposomes encapsulation of enriched phenolic fraction from pistachio hulls and its antioxidant, anti-inflammatory, and antimelanogenic activities. Journal of microencapsulation 2020, 37:1-13.

27. Shafaei N, Barkhordar SMA, Rahmani F, Nabi S, Idliki RB, Alimirzaei M, Karimi E, Oskoueian E: Protective Effects of Anethum graveolens Seed's Oil Nanoemulsion Against Cadmium-Induced Oxidative Stress in Mice. Biological Trace Element Research 2020:1-9.

28. Livak KJ, Schmittgen TD: Analysis of relative gene expression data using real-time quantitative PCR and the $2-\Delta \Delta$ CT method. methods 2001, 25:402-408.

\section{Figures}




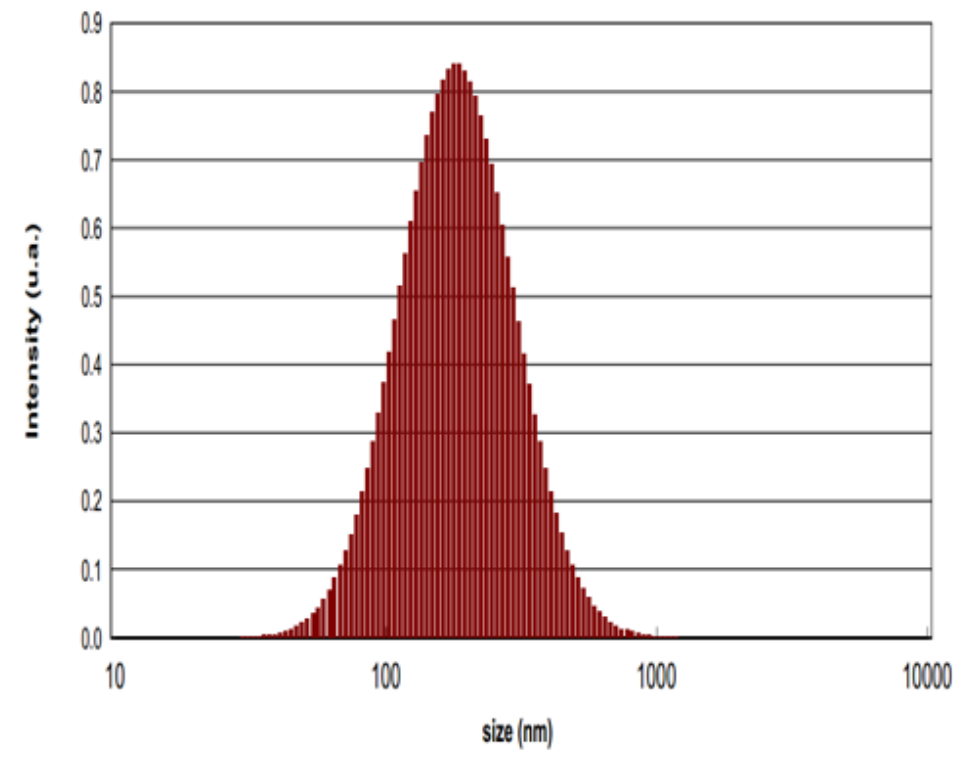

$\mathbf{A}$

\section{Figure 1}

Characteristic features of nanophytosomes

T1

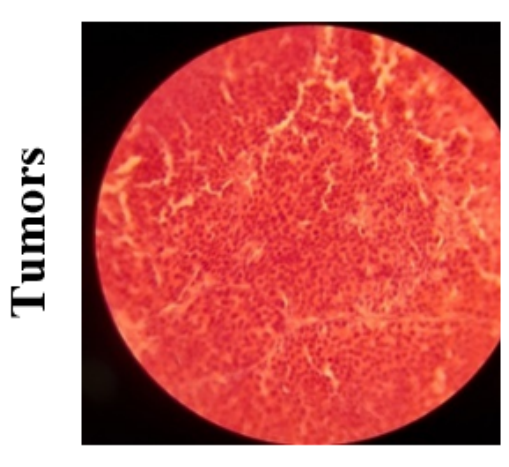

T2

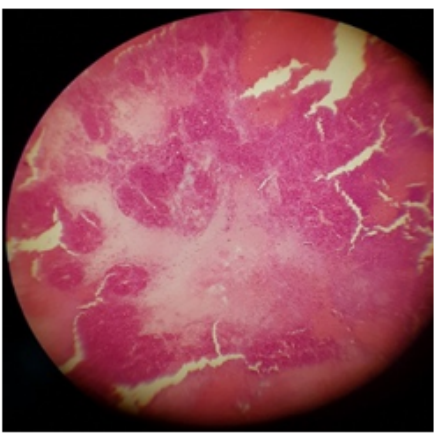

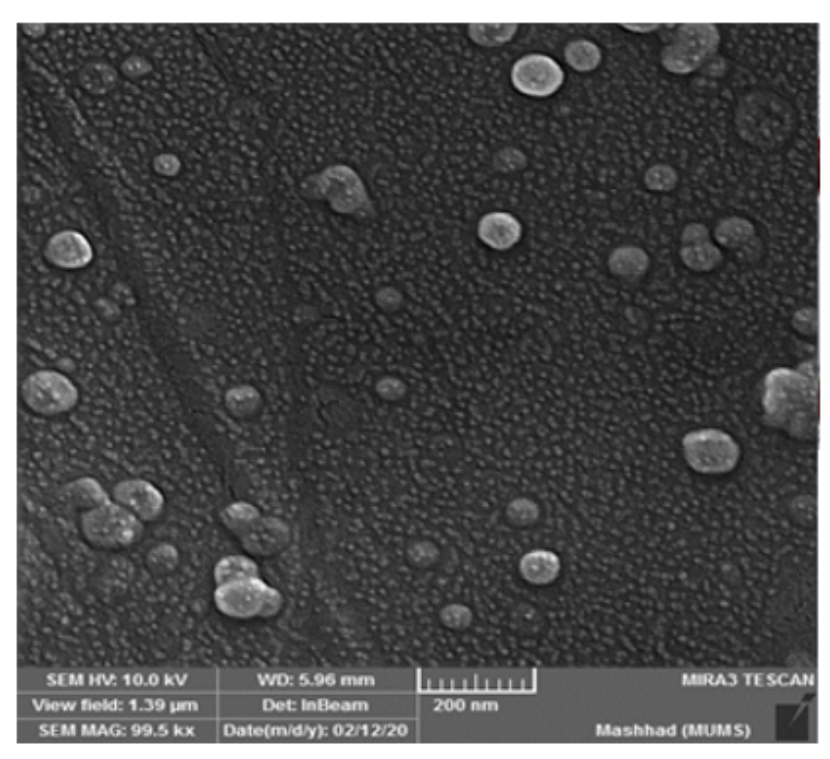

B
T3

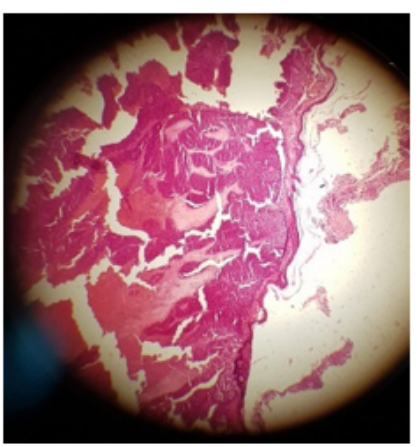

T4

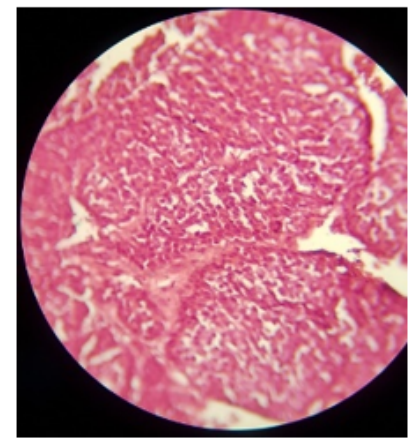

Figure 2

The histopathological changes in the TUBO tumor-bearing mice during experiments receiving different treatments. Control (T1); mice receiving HPF (50 mg TPC/Kg/BW) (T2); mice were receiving nanophytosome-loaded HPF (50 mg TPC/Kg/BW) (T3); and mice receiving tamoxifen $(0.4 \mathrm{mg} / \mathrm{kg} / \mathrm{BW}$ similar dose to the clinical dose in humans) as an antiproliferative drug (T4). 


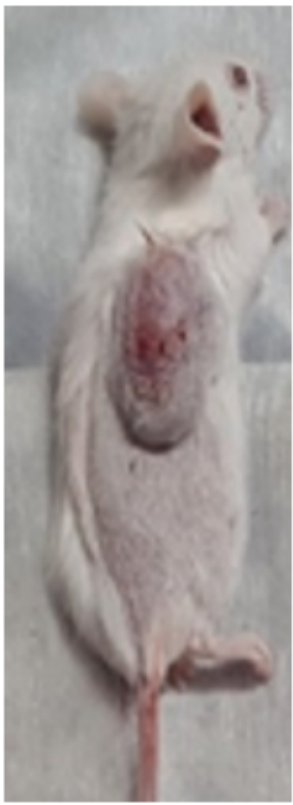

T1

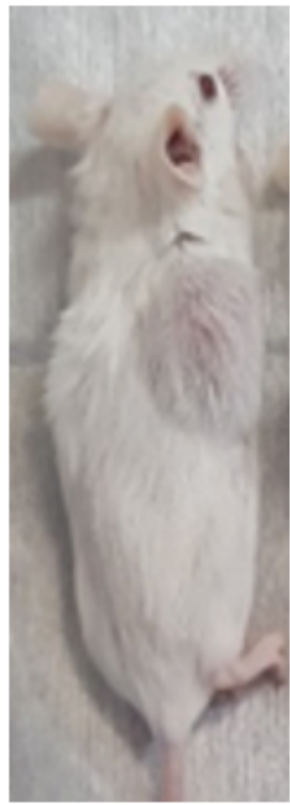

T2

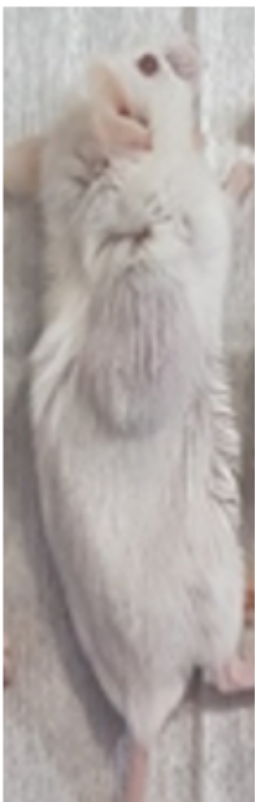

T3

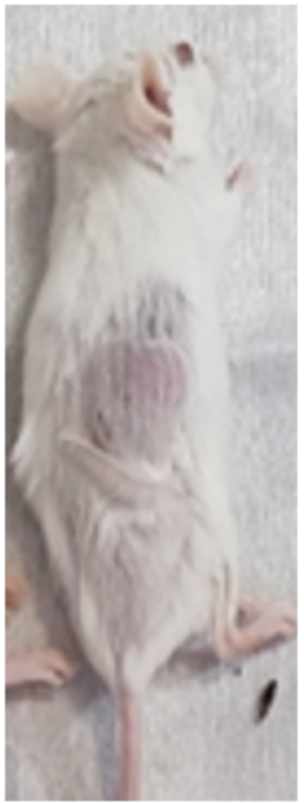

T4

\section{Figure 3}

Comparison of the tumor size in TUBO tumor-bearing mice during experiments receiving different treatments. Control (T1); mice receiving HPF (50 mg TPC/Kg/BW) (T2); mice were receiving nanophytosome-loaded HPF (50 mg TPC/Kg/BW) (T3); and mice receiving tamoxifen $(0.4 \mathrm{mg} / \mathrm{kg} / \mathrm{BW}$ similar dose to the clinical dose in humans) as an antiproliferative drug (T4).

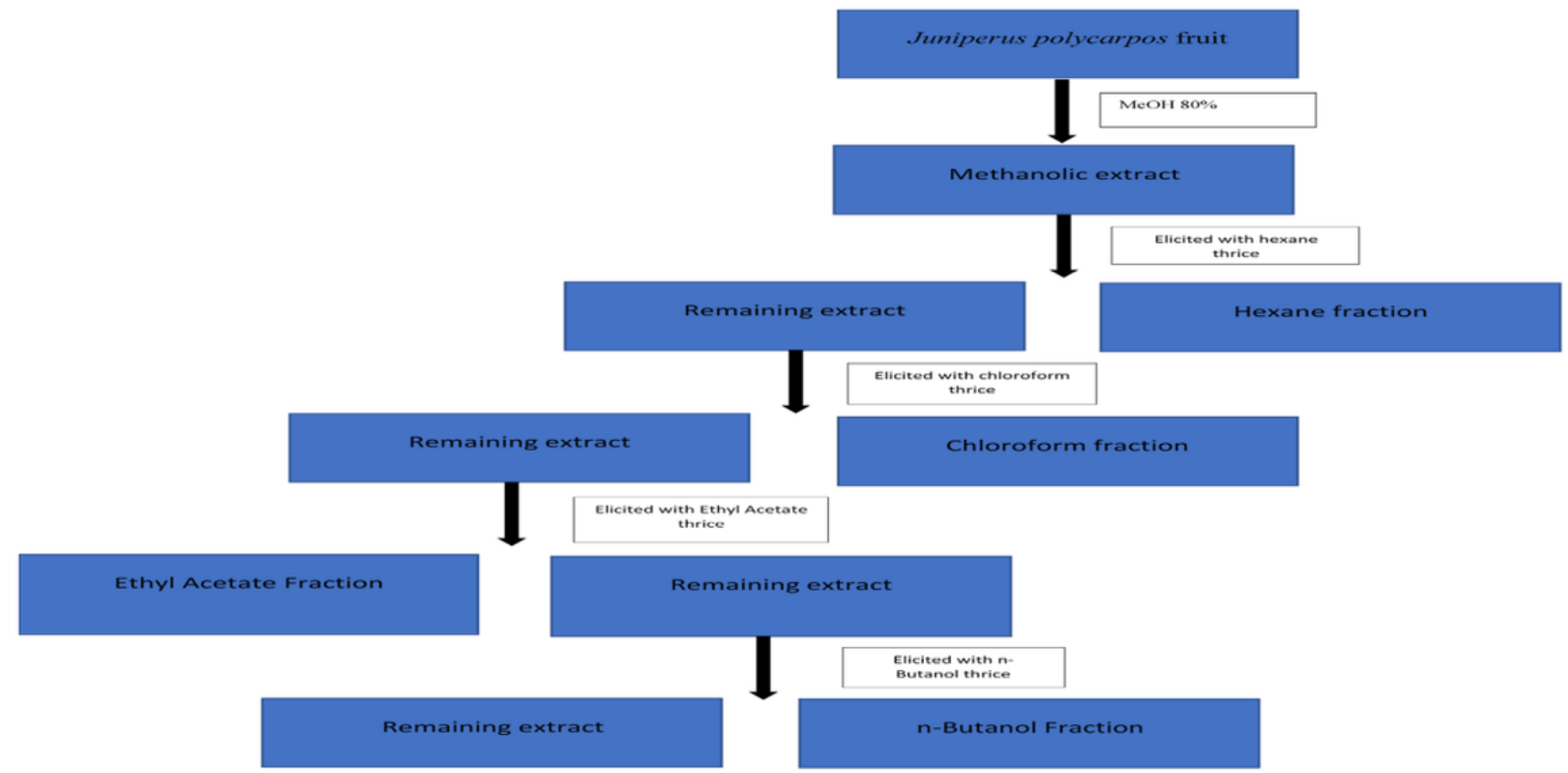

Figure 4 
Fractionation procedure

\section{Supplementary Files}

This is a list of supplementary files associated with this preprint. Click to download.

- GraphicalAbstract.jpg 